\title{
New Carbon- and Sulfur-based Ligands in Catalysis
}

\author{
Reto Dorta* \\ Werner Prize Winner 2011
}

\begin{abstract}
Homogeneous catalysis is a field of research that has gained central importance in both organic and inorganic chemistry and the use of well-defined ligand systems in the synthesis of transition metal complexes has had an enormous impact on the development of such catalysts. Neutral, two-electron donor ligands based on phosphorous and nitrogen have been tremendously successful as ancillary entities for late-transition metal (LTM) catalysts, whereas ligands based on anionic nitrogen, oxygen and the cyclopentadienyl motif (Cp-) have propelled early-transition metal (ETM) catalysis forward. We believe that expanding the ligand families capable of acting as successful entities in metal-mediated reactivity and catalysis is crucial for future discoveries in this field. Research in our group therefore tries to identify new non-chiral and chiral ligands for late-transition metal chemistry that are based on neutral, two-electron carbon and sulfur donor atoms. In particular, we have until now focused on the development of modular, monodentate $\mathrm{N}$-heterocyclic carbene ligands (NHCs) that can serve as a basis for the development of chiral ligand frameworks for the application to asymmetric catalytic transformations. In the second major research project developed over the last six years, we have started an investigation on the use of chelating sulfoxide-based ligands in asymmetric late transition-metal based catalysis.
\end{abstract}

Keywords: Asymmetric synthesis · N-Heterocyclic carbenes · Homogeneous catalysis · Sulfoxides

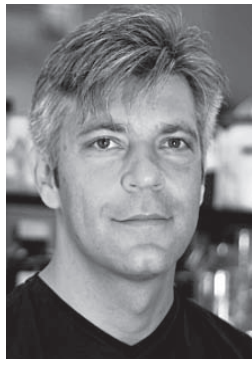

Reto Dorta studied chemistry at the University of Neuchatel and the University of Salerno (Erasmus student year). He joined the groups of Professor Helen Stoeckli-Evans and Professor Georg Süss-Fink at the University of Neuchatel for his Diploma work (1997) and subsequently moved to the Weizmann Institute of Science, where he earned his doctoral degree under Professor David Milstein in 2002. He then transferred to the University of New Orleans for a one-year postdoctoral stay with Professor Steven P. Nolan. Soon after joining Professor John E. Bercaw at the California Institute of Technology for a second postdoctoral research stay, he

${ }^{*}$ Correspondence: Prof. Dr. R. Dorta

Organic Chemistry Institute

University of Zurich

Winterthurerstrasse 190

$\mathrm{CH}-8057$ Zurich

Tel.: +41446353941

E-mail: dorta@oci.uzh.ch

New Address:

School of Biomedical, Biochemical and Chemical

Sciences

University of Western Australia

35 Stirling Highway

Crawley, WA, 6009, Australia

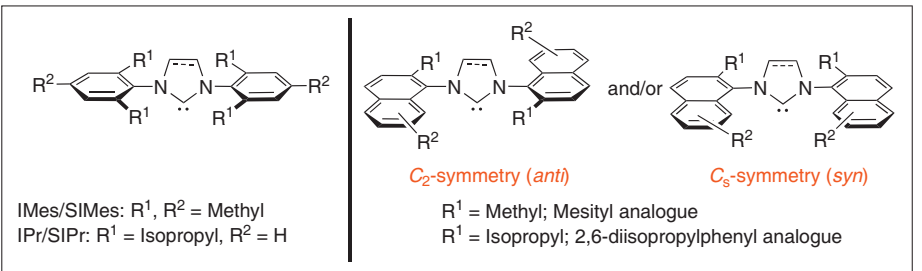

Scheme 1. Design principle for new saturated and unsaturated $\mathrm{N}$-heterocyclic carbenes.

was awarded an Alfred Werner Assistant Professorship and moved to the Organic Chemistry Institute at the University of Zurich in May 2005. He was awarded the Thieme Chemistry Journal Award in 2009 and the Werner Prize in 2011. The ultimate goal of his research program is to identify new ligand families and their corresponding metal complexes for new, more selective or more widely applicable catalytic transformations. Very recently, he has accepted an Associate Professor position at the University of Western Australia where he will continue his research on these topics.

\section{New N-Heterocyclic Carbene Ligands in Late-transition Metal Chemistry}

\subsection{Introduction}

The chemistry of N-heterocyclic carbenes (NHC) and, in particular their application as ligands in late-transition metal chemistry, has developed rapidly since the first synthesis of an isolable carbene species of this type by Arduengo et al. in
$1991,{ }^{[1,2]}$ and has put this ligand class at the forefront of current research efforts. ${ }^{[3-5]}$ Arguably the most common applications of NHCs and their relatives are as ancillary ligands for achiral metal-mediated catalysis. ${ }^{[6]}$ Reactions incorporating NHC metal complexes represent some of the most significant advances in homogeneous catalysis during the last decade, particularly for ruthenium-catalyzed alkene metathesis and for palladium-catalyzed coupling reactions. A survey in the literature however shows that most of the N-heterocyclic carbene ligands synthesized in the past decade suffer from rather limited applicability and/or reactivity. In fact, mesityl- and 2,6-isopropylphenyl-substituted NHCs (IMes/SIMes and IPr/SIPr) are the only truly versatile and successful designs to date (Scheme 1). This very restricted architectural choice is hindering in particular development of chiral monodentate NHCs, a field of research that is still awaiting the breakthrough of NHC ligand classes combining good chiral induction and high versatility. ${ }^{[7-14]}$

Research on new NHC ligands in our group has therefore been targeting both 
these restrictions. When thinking of the best way for not only proposing viable alternatives to the successful NHC designs currently available, but also to come up with possibly good chiral NHC candidates, we have decided to target structures that instead of incorporating mesityl/2,6isopropylphenyl side chains would rely on substituted naphthyl wingtips instead. In doing so, we would indeed create potentially chiral, $C_{2}$-symmetric NHCs as shown in Scheme 1.

\subsection{Synthesis and Stability of the First Imidazolin-2-ylidene Ligand Members with Naphthyl Wingtips}

Most carbene structures based on saturated imidazolin-2-ylidenes dimerize readily to give enetetramines and very few stable imidazolin-2-ylidene are therefore known in the literature. ${ }^{[15-19]}$ The synthesis of imidazolin-2-ylidene (saturated NHCs) containing 2- or 2,7-substituted naphthyl wingtips and their precursor salts followed short synthetic routes (Scheme 2). ${ }^{[20,21]} \mathrm{At}$ least as long as position 2 of the naphthyl wingtips contains an alkyl group, deprotonation of the imidazolinium salts with base leads to clean formation of the free, monomeric N-heterocyclic carbenes. ${ }^{[22]}$ This is true not only for the first members of this ligand family depicted in Scheme 2, but for a variety of closely related ligands we have synthesized so far. ${ }^{[23,24]}$ The size of the substituent in position 2 seems to influence both the ease of interconversion of $C / C$-isomers as well as the relative ratio with which the corresponding isomers are formed in the ring-closing step leading to the NHC salt. For example, $(2,7)$ SIPrNap already does not interconvert when heated, while introducing an even bulkier group in position 2 leads to ligands where the $C_{2}$ isomer can be highly favored over the $C_{s}$ isomer (syn). These results boded well for studies on enantiomerically pure versions of these ligands (see below).

\subsection{Selected Catalytic Applications}

As a first performance test, the three new NHC ligands shown in Scheme 2 were used in representative catalytic applications which included NHC-palladium-catalyzed coupling reactions, ${ }^{[25-28]}$ ring-closing olefin reactions with Grubbs' second-generation NHC-ruthenium complexes, ${ }^{[29-32]}$ as well as organocatalytic ring-opening alkylation of epoxides catalyzed by these NHCs. ${ }^{[33-35]}$ Excellent catalytic results were obtained in all these transformations and among the three NHC structures tested, the isopropyl-modified naphthyl wingtips in (2,7)-SIPrNap stood out as being a particularly effective ligand design.

At this point and because of the very interesting catalytic activities seen with $(2,7)$-SIPrNap, we decided to divide the

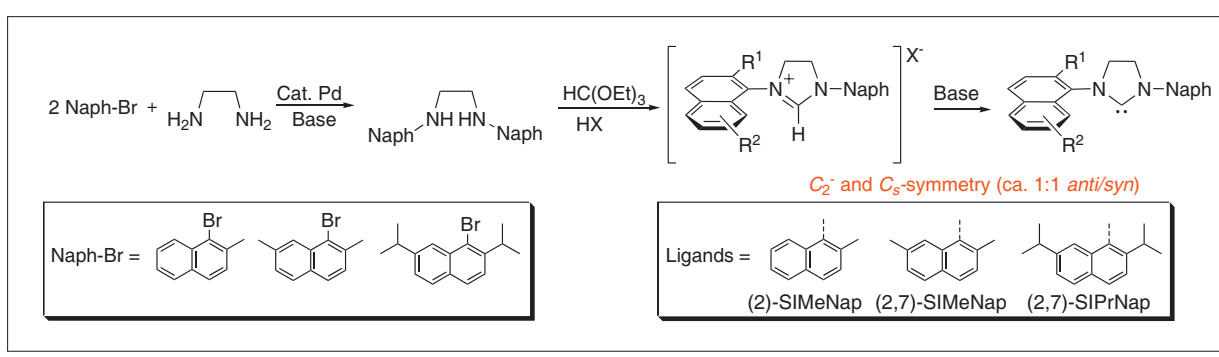

Scheme 2. Synthetic pathway to first-generation imidazolin-2-ylidenes with naphthyl side chains.

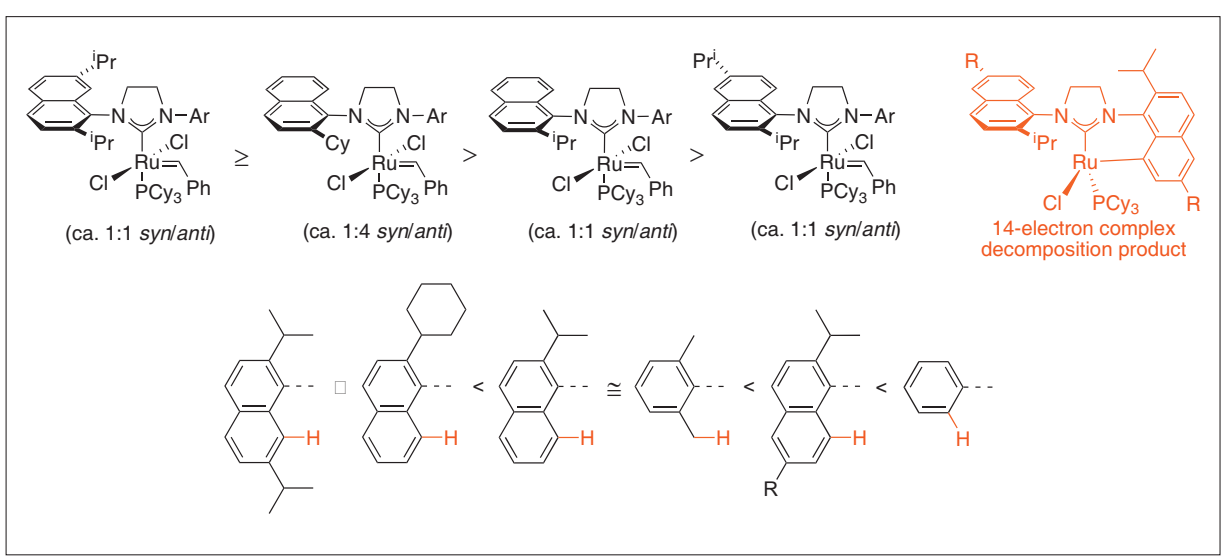

Fig. 1. Overall order of RCM activity depending on NHC side chains (above left), isolated decomposition product with 2,6-substituted naphthyl wingtips (above right) and plausible order of catalyst decomposition via $\mathrm{C}-\mathrm{H}$ activation of the $\mathrm{NHC}$ side chains (below).

NHC project. One part would focus on developing non-chiral catalysis further by tackling challenging or unresolved catalytic problems. The other part of the project would directly start to evaluate enantiomerically pure NHC ligands based on the naphthyl wingtip architecture in asymmetric catalytic transformations.

\subsection{New NHC Ligands in Ruthenium-catalyzed Ring-closing Metathesis}

Especially interesting results in the preliminary study were obtained in the ruthenium-catalyzed ring-closing metathesis. Together with the fact that metathesis is becoming a more and more prominent reaction in chemistry, it certainly served as a perfect entry point into this fascinating field of research. Our idea was to see how small variations to the so far best NHC ligand, $(2,7)$-SIPrNap, would affect the overall performance of GII (Grubbs II, where NHC = SIMes) type analogues in RCM.

These first studies revealed that indeed an intimate relationship between the substitution pattern of the side chains and the activity/stability of the resulting complexes in RCM exists. ${ }^{[36,37]}$ Among ligands with 2-substituted naphthyl moieties, the one incorporating cyclohexyl outperforms the isopropyl analogue. The worst ligand in terms of stability (and reactivity) turned out to have a 2,6-substitution pattern on the naphthyl units, as it was shown to undergo relatively easy $\mathrm{C}-\mathrm{H}$ activation at the 8-position, giving a metathesis inactive species (Fig. 1). Extrapolating these data to known SIMes would indicate that correctly substituted naphthyl side chains permit a more effective control and minimization of available carbon-hydrogen bonds that react irreversibly with the ruthenium center.

An open question from these results remained as we did not know whether an anti-configuration ( $C_{2}$-symmetry) or a syn-geometry ( $C$-symmetry) of the NHC ligand would be preferred in terms of activity/stability. To separate such isomeric complexes and at the same time understand where the limits lie in terms of activity, we decided to prepare phosphine-free ruthenium precatalysts that are analogues to the fast-initiating SIMes-derived Blechert catalyst (BleII, Scheme 3). ${ }^{[38]}$ RCM results depicted in Fig. 2 indeed show that NHC ligands with an anti-configuration of the side chains are superior. While testing other substrates further, we also established that RCM giving 5- or 6-membered rings could be significantly accelerated when using more concentrated reaction conditions. In practice, this means that RCM can now be performed with low catalyst loadings (50-250 ppm) at room temperature and reaches impressive TOFs of up to $67 \mathrm{~s}^{-1}$. $^{[39]}$

During the studies undertaken with these second-generation ruthenium complexes, we came across catalytic results that redirected our efforts towards RCM 
reactions currently still not available or not practical. Indeed, we found a very easy method to overcome some of the serious limitations associated with RCM reactions that produce cyclic vinyl chlorides. At the same time, we have developed an efficient method for producing synthetically even more valuable cyclic vinyl bromides via RCM (Scheme 4). This unknown RCM transformation is now easily achieved by using a commercially available catalyst, relatively low catalyst loadings (1-2 mol\%) and short reaction times (<30 $\mathrm{min}){ }^{[40]}$

\subsection{Room-temperature Suzuki- Miyaura Cross-coupling to give Tetra-ortho-biaryl Products}

Encouraged by the results of $(2,7)$-SIPrNap and (2)-SICyNap ligands in ruthenium metathesis, we decided to test some of our more bulky NHC ligands in difficult palladium-catalyzed coupling reactions. As a first application, these new ligands were used in very challenging Suzuki-Miyaura cross-coupling reactions that generate tetra-ortho-substituted biaryl products. ${ }^{[41,42]}$ These studies have led to the identification of an NHC structure with 2,7-cyclooctyl-substituted naphthalene wingtips, ${ }^{[24]}$ that outperforms any of the known and/or commercially available ligands or ligand/metal combinations. Indeed, reactions can now be run conveniently and with high isolated yields at room temperature (Scheme 5). ${ }^{[43]}$ These latest results clearly underline the special characteristics of such naphthyl-substituted NHCs, which we believe is due to the basic design permitting a more accurate modulation of the steric characteristics of the ligand scaffold. We are confident that other difficult as well as new transformations will become available when such optimized ligands are employed.

\subsection{First Studies on Chiral NHC Derivatives; Palladium-catalyzed $\alpha$-Arylation}

Our studies on naphthyl-derived NHC structures showed that $C_{2}$ - and $C$-symmetric structures exist and do not interconvert. Logically, if the chiral regime of $C_{2}$-symmetric diamines is introduced to the heterocyclic backbone of these NHCs, three diastereomers should be generated. We therefore embarked on such a study and prepared the corresponding $(\mathrm{NHC}) \mathrm{Pd}(\mathrm{cin}) \mathrm{Cl}$ complexes. Indeed, these compounds exist as a mixture of diastereomers and the palladium complexes could be successfully separated and their absolute stereochemistry assigned. The resulting compounds were tested in the asymmetric intramolecular $\alpha$-arylation of amides and led to the identification of a precatalyst $\left[\left(R_{a}, R_{a}\right)-[\mathbf{P d}]\right]$ that formed oxindoles in high yield and high enantio-

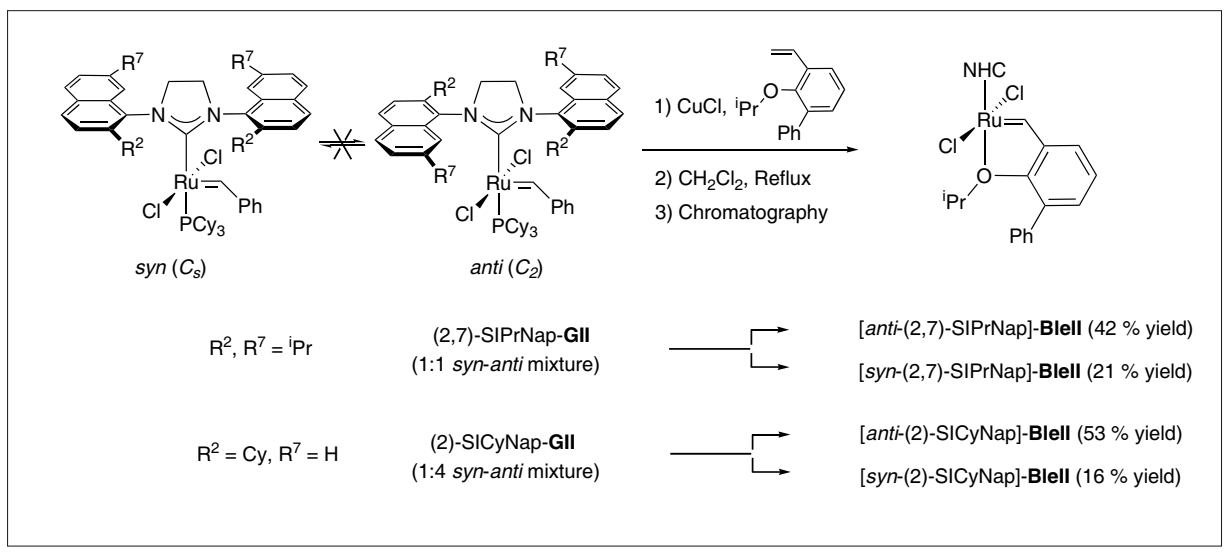

Scheme 3. Separable syn- and anti-NHC complexes of second-generation ruthenium metathesis catalysts.

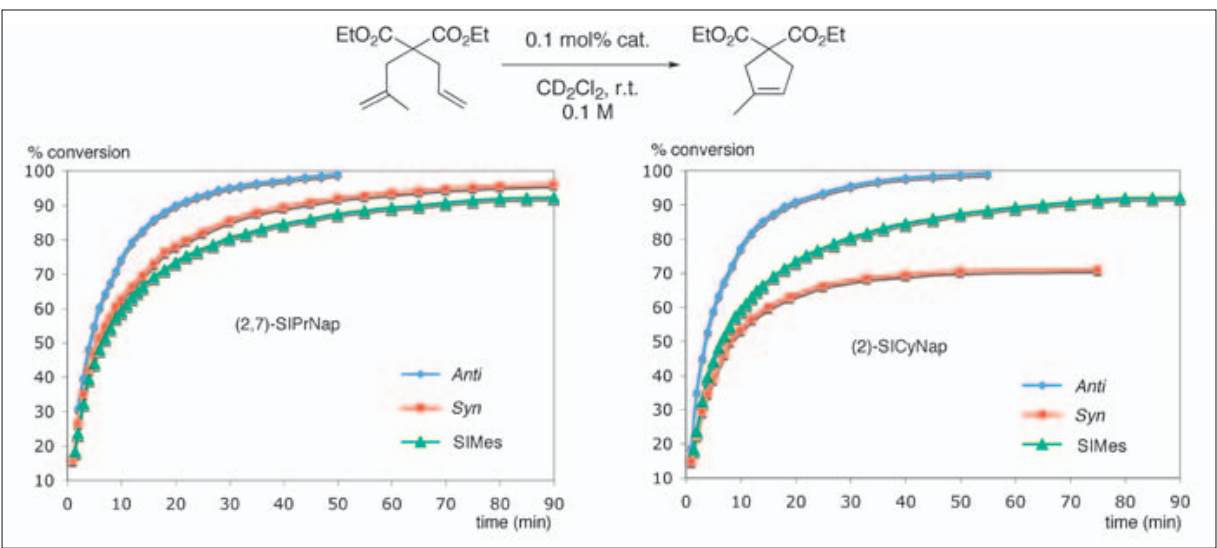

Fig. 2. Time-conversion curves (established via ${ }^{1} \mathrm{H}$ NMR spectroscopy) for anti- and syn-isomers of [NHC]-Blell complexes.

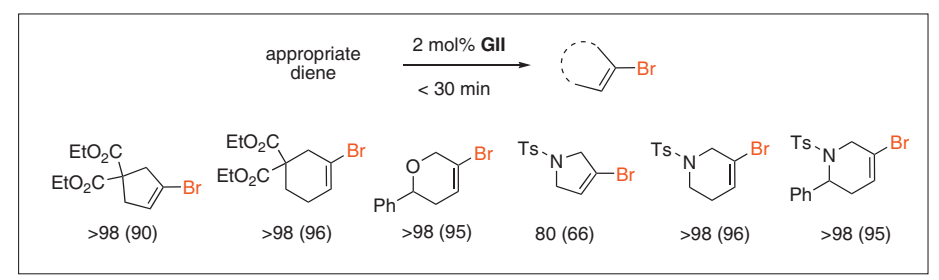

Scheme 4. Results on the RCM leading to cyclic vinyl bromides (isolated yields in brackets).

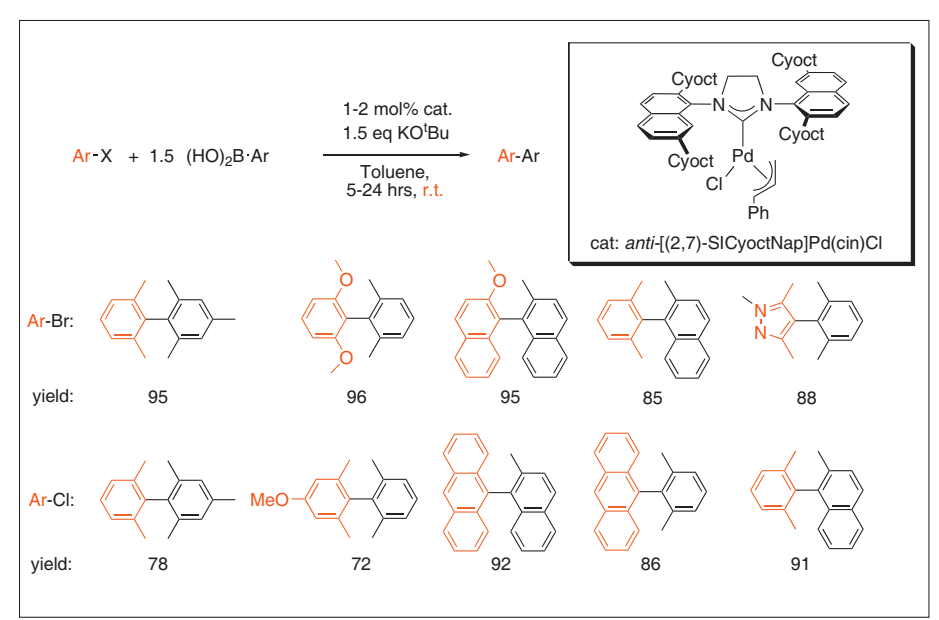

Scheme 5. Roomtemperature preparation of tetraortho-substituted biaryl compounds via Suzuki-Miyaura cross-coupling (isolated yields).

meric purity (Scheme 6). Analysis of the catalytic data demonstrated the dramatic effects on selectivity the orientation of the aromatic side chains can have in catalysis and detailed results can be found in the literature. ${ }^{[44]}$
While elegant as a methodology to obtain chiral quaternary carbon centers, the intramolecular $\alpha$-arylation has the drawback of providing oxindoles that are difficult to functionalize further. We therefore wondered whether 3-allyl-3-aryl oxin- 
doles, previously only accessible via a twostep procedure involving a Pd-catalyzed intramolecular $\alpha$-arylation followed by an asymmetric Pd-catalyzed allylic alkylation, could be obtained directly. At the outset, it was not clear whether such $\alpha$-arylations would be preferred over a reaction scenario involving Heck cyclizations giving rise to 7-exo-trig (or 8-endo-trig) products (Scheme 7). First results indeed showed that this secondary reaction pathway was competitive and relatively high amounts of the Heck product were produced (10 $20 \%$ ) when employing our previously reported catalysts. A slight modification of the naphthyl side chain though, namely the introduction of a 3-pentyl group in position 2 of each naphthyl wingtip, elegantly solved this problem. The palladium complexes derived from this ligand combine excellent reactivity with high chemo- and enantioselectivity for the title transformation and these results have been communicated recently. ${ }^{[45]}$

Evidently, these first very encouraging catalytic results with enantiomerically pure, monodentate NHC ligands will serve as the basis for our future efforts in this field of research.

\section{Chiral, Chelating Sulfoxide Ligands in Late-transition Metal Catalysis}

\subsection{Introduction}

Chiral ligand systems in metal-catalyzed reactions provide the most elegant way to produce enantiomerically pure products, because one chiral catalyst molecule can create millions of chiral molecules, just as enzymes do in biological systems. At present, chiral and chelating phosphine and nitrogen ligands play by far the most important role for stabilizing the relatively soft late-transition metal (LTM) centers.[46,47] Sulfur-containing ligand molecules, on the other hand, have long been considered a poison for metal catalysis and have therefore received comparatively little attention. As a consequence, when we started our investigations very few examples existed in which sulfoxides (chiral or non-chiral) participate in homogeneous catalysis and Fig. 3 shows the most prominent and relevant results obtained in the last decades. ${ }^{[48-53]}$ This fact is rather perplexing since sulfoxides, within a chelating, bidentate ligand framework, present many advantages: (i) the source of chirality is at sulfur, (ii) there is a wealth of chemistry associated with the preparation of optically pure sulfoxides, and (iii) their $\sigma$-donor/ $\pi$-acceptor properties (bound through sulfur) seem to be well-suited for stabilizing LTMs. Indeed, even chelating ligand systems that incorporate mixed

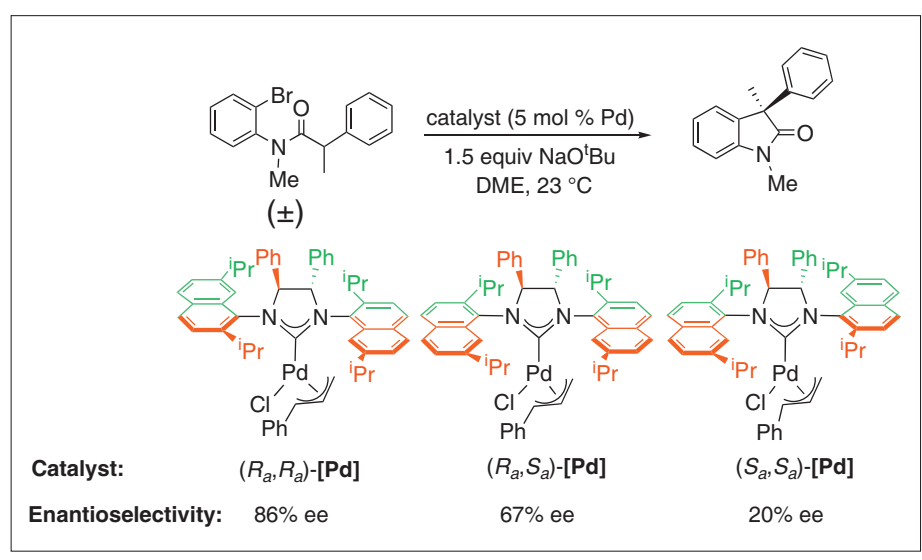

Scheme 6. Impact of isomeric $\mathrm{NHC}$ structures on the selectivity of the palladium-catalyzed asymmetric $\alpha$-arylation reaction.

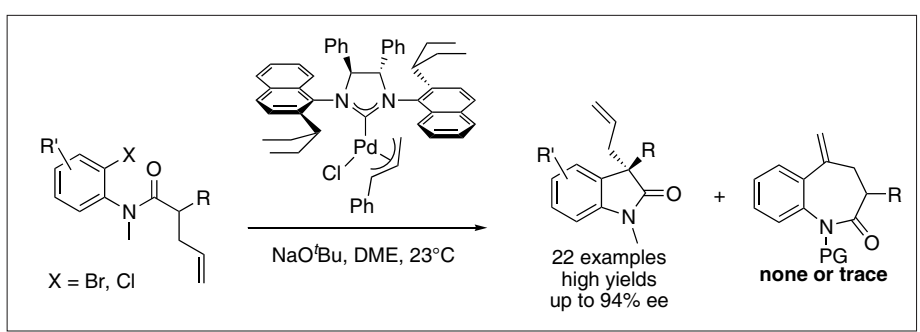

Scheme 7.

Asymmetric $\alpha$-arylation leading to functionalizable oxindole products.

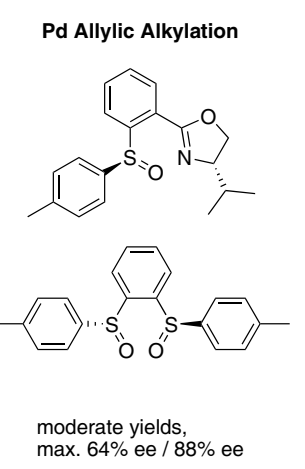

Pd Allylic Alkylation

DIOS, $\mathrm{R}=\mathrm{Me}$<smiles>[R]PS(=O)C[C@H](O)[C@@H](O)CS(=O)O</smiles>

low yields, max. $25 \%$ ee (with Ru, ulfoxides used as racemates)
Rh transfer hydrogen. Ir transfer hydrogen.<smiles>[R]PS(=O)CCC(NC)C(=O)O</smiles><smiles>NC(CO)CS(=O)Cc1ccccc1</smiles>

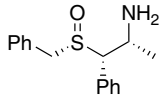

low yields, $\max 75 \%$ ee low to good yields, $\max 80 \%$ ee

Fig. 3. Most interesting previous results in catalysis with chiral sulfoxide-containing ligands.

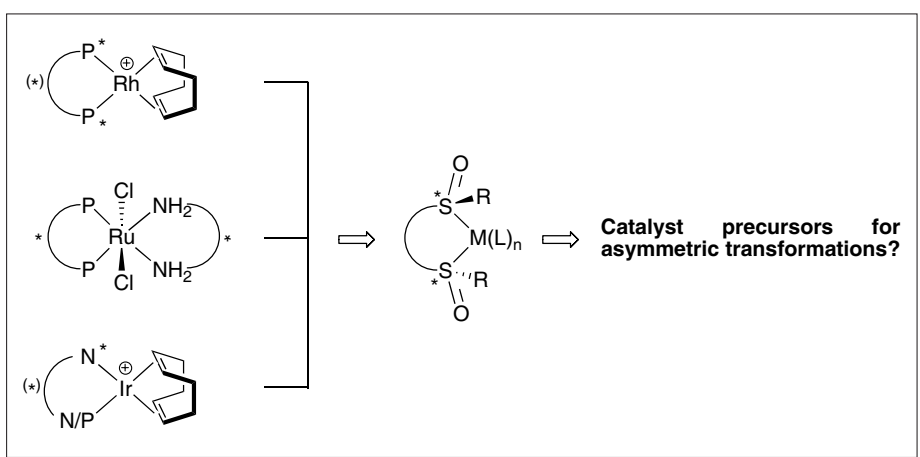

Fig. 4. Schematic approach for introducing chiral disulfoxide ligands.

sulfoxide/phosphine or sulfoxide/nitrogen donors are rare in the literature and testify to how the sulfoxide moiety has been neglected with regards to its role as ligating moiety to metal centers. ${ }^{[54-61]}$

While the results in the literature over the last decades did not bode well for developing successful ligands based on sulfoxides, these earlier attempts clearly left enough room for our own group's efforts to succeed (Fig. 4).

\subsection{Chiral Disulfoxides in the Miyaura-Hayashi Reaction}

In the last five years, we have started investigating the potential of chelating disulfoxide ligands with atropisomeric backbones in asymmetric late-transition metal chemistry. More specifically, we have developed the rhodium-catalyzed 1,4-addition of arylboronic acids to cyclic $\alpha, \beta$-unsaturated compounds. ${ }^{[62]}$ Pioneered by Miyaura and Hayashi a decade ago, this 

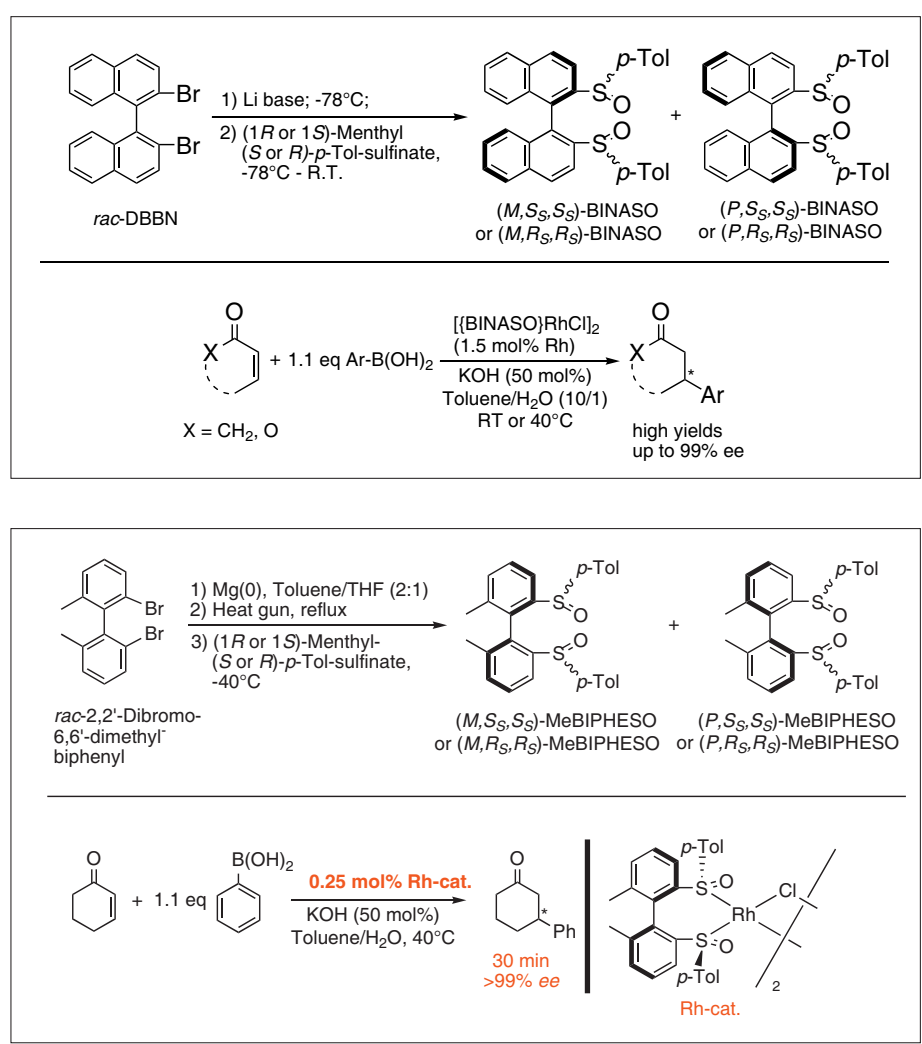
ligand and rhodium

reaction represents a very straightforward entry into useful chiral organic building blocks and has emerged as an important methodology in organic synthesis.

The disulfoxide ligand used in our first catalytic application is a 1,1'-binaphthyl derivative similar to the well-known and extremely successful BINAP (1,1'-binaphthalene-2,2'-diyl-bis-diphenylphosphine) ligand developed by the Noyori group. ${ }^{[62,63]}$ Compared to BINAP, synthesis of the disulfoxide analogue called BINASO is extremely straightforward and can be done in one single step from commercially available starting materials according to Scheme 8. The corresponding rhodium complex incorporating BINASO was then used in the Miyaura-Hayashi addition reaction of arylboronic acids to cyclic $\alpha, \beta$-unsaturated compounds, combining extremely easy ligand synthesis with excellent catalytic activities and selectivities.

Building upon these results and in analogy to research done with diphos-
Scheme 9

Synthesis of the $p$-Tol-MeBIPHESO catalysis.

Scheme 8. Synthesis of the $p$-Tol-BINASO ligand (above) and use of the rhodium complex thereof in the Miyaura-Hayashi reaction (below). catalys. phines, we decided to slightly modify the atropisomeric backbone in order to test its impact on reactivity and selectivity of the rhodium precatalyst and chose BIPHEMP (dimethyl-biphenyl-2,2'-diylbis(diphenylphosphine) as our template (Scheme 9).[64] The corresponding rhodium catalyst system showed even higher reactivity and selectivities in these transformations, often producing the other enantiomer in such tiny amounts that it could not be detected by standard analytical methods (HPLC). ${ }^{[65,66]}$

These results subsequently prompted us to go back and try to understand the characteristics of this catalyst system in more detail. As a first step, we wanted to quantify to what extend sulfoxides are able to donate electron-density to rhodium and therefore synthesized cationic carbonyl complexes of general formula [(L$\left.\mathrm{L}) \mathrm{Rh}(\mathrm{CO})_{2}\right]^{+} .{ }^{[67]}$ In line with expectations, substituting the fused aromatic rings of the $p$-Tol-BINASO backbone with $\mathrm{sp}^{3}$-hybrid- ized carbon atoms in $p$-Tol-MeBIPHESO leads to increased electron-donation to the rhodium. Likewise, varying the substitution on the sulfoxide moiety while keeping the backbone unchanged follows trends expected based on electronic arguments. The introduction of electron-withdrawing groups such as fluorine and trifluoromethyl in the para position of the phenyl ring of the sulfoxide leads to diminished electron-density on the metal center, while electron-donating groups or substitution of the parent $p$-tolyl moiety with a cyclohexyl group increase the electron-density at rhodium. The most surprising results of this study revealed that the carbonyl stretching frequencies of the disulfoxide-containing complexes are lower than for the corresponding phosphine compounds, meaning that aryl-disulfoxides $p$-Tol-MeBIPHESO and $p$-Tol-BINASO. ${ }^{68]}$

Reactivity studies have also shown that the diphosphine compounds are distinctly less active than the systems incorporating disulfoxides under the reaction conditions used, with generation of the active catalyst being more difficult to achieve (A of Scheme 10).[69,70] More intriguing than the higher reactivity of these disulfoxide ligands though seems to be their mode of action during the enantiodiscriminating step (C of Scheme 10). The stereochemical pathway in the Miyaura-Hayashi reaction catalyzed by BINAP as well as in the overwhelming majority of metal-mediated asymmetric reactions is based on the assumption that the substrates approach the metal so as to minimize steric interactions with the protruding $\mathrm{R}$ groups of the chiral ligand structure (quadrant rule). However, the half view of our rhodium disulfoxide complexes shown above (see partial views in Scheme 10) clearly indicates that our system is devoid of any significant steric crowding around the metal center. Indeed, the aryl groups on the sulfoxide units are oriented away from the metal center and parallel to the atropisomeric backbone, leaving the oxygen atoms of the sulfoxide moieties as the sole entities approaching the metal center.

Advanced DFT calculations in collaboration with Prof. Cavallo's group on the

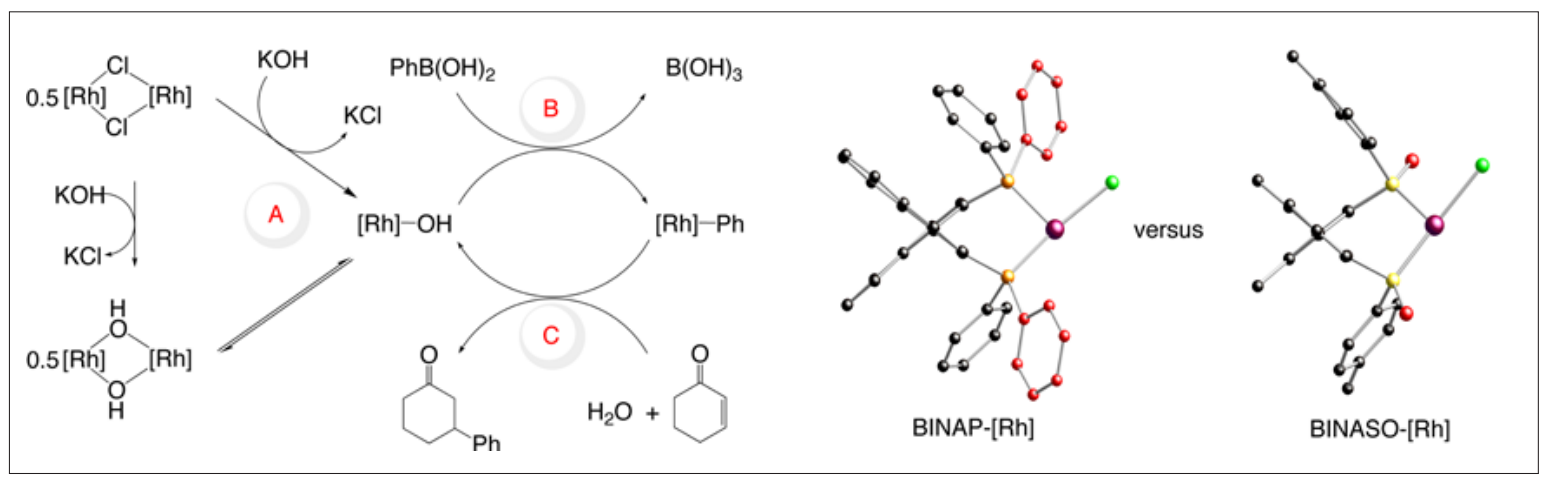

Scheme 10. Reaction pathway in the Miyaura-Hayashi reaction (left) and partial views of BINAP-[Rh] and BINASO-[Rh] complexes (red color shows sterically relevant groups). 
reaction path have uncovered the mechanism by which these disulfoxide-rhodium catalysts discriminate between the two possible enantiomeric products and results have been published recently. ${ }^{[67,71]}$ Indeed and contrary to more traditional chiral ligand frameworks, electronic factors arising from the sulfoxide moiety are partially responsible for the high enantioselectivities observed in catalysis. Furthermore, it is not the initial binding of the olefin, but the following insertion in step $\mathbf{C}$ (Scheme 10) that discriminates between the possible enantiomers. These findings should prove useful for future research in the use of sulfoxide-based ligands, allowing a rational design of structures that take advantage of the phenomenon described here. Several other aspects of this first application of chiral disulfoxide ligands in late-transition metal catalysis are still under scrutiny and will be reported in due time.

\subsection{Chiral Disulfoxide Ligands in Other Reactions}

In parallel to our efforts in the Michaeltype addition chemistry with rhodium (Miyaura-Hayashi reaction), we have begun looking at other potential uses for disulfoxide ligands. We have indeed already found a catalytic application where these disulfoxide ligands show excellent reactivity, albeit with modest selectivities so far. While still in the works, it is interesting to note that in this particular transformation, more established diphosphine or $\mathrm{P} / \mathrm{N}$ ligands did not show any reactivity, meaning that complimentary or new reactivity can indeed be achieved with the disulfoxide ligand class.

\section{Summary and Outlook}

In summary, our first two research projects dealing with synthesis and application of new carbon- and sulfoxide-based ligands have been successfully launched. The next level, which includes the development of new catalytic processes or useful variations of existing ones, has begun and will run parallel to traditional ligand fine-tuning. Furthermore, we expect soon to go back to look at stoichiometric reactivity incorporating our ligands that will establish trends and possible opportunities for both these ligand classes. Synergies between NHCs and sulfoxides might also exist and open new exciting venues in the future.

\section{Acknowledgement}

I would like to dedicate the Alfred Werner Prize to all the students and collaborators involved in the research that is described in this article. In chronological order, the persons working in the group were/are: Dr. Ronaldo Mariz (PhD student), Dr. Xinjun Luan (PhD student), Dr. Chiara Costabile (sabbatical research stay), Dr. Michele Gatti (PhD student), Dr. Ludovic Vieille-Petit (Postdoctoral researcher), Carine Robert (summer student), Justus Bürgi (master student), Dr. Emma Drinkel (PhD student), Linglin $\mathrm{Wu}(\mathrm{PhD}$ student), Mirella Bigi (master student), Fiona Gaggia (laboratory apprentice), Ivano Pusterla ( $\mathrm{PhD}$ candidate), Christoph Edlinger ( $\mathrm{PhD}$ candidate), Samanta Capolicchio (PhD student), Geraldine Labrador (summer student). It is their dedication and enthusiasm that has made all of this possible. Furthermore, I would like to thank the following collaborators for their invaluable contributions: Prof. Dr. Luigi Cavallo, Dr. Albert Poater, PD Dr. Anthony Linden, Prof. Dr. Romano Dorta, Prof. Dr. Kim K. Baldridge, Prof. Dr. Jay S. Siegel. Special thanks go to the Alfred Werner foundation for the award of an Assistant Professorship and to Prof. Jay S. Siegel, who invited me to start my career at the Organic Chemistry Institute and to all of the members of the Institute for their support along the way. Crucial financial support came from the Organic Chemistry Institute, the Swiss National Science Foundation and the Roche Research Foundation. Particular thanks go to Dr. Michelangelo Scalone, Dr. Martin Karpf and Dr. Kurt Püntener for generous direct funding from F. Hoffmann La Roche.

Received: August 17, 2011

[1] A. J. Arduengo III, R. L. Harlow, M. Kline, $J$. Am. Chem. Soc. 1991, 113, 361.

[2] A. J. Arduengo III, Acc. Chem Res. 1999, 32, 913.

[3] 'N-Heterocyclic Carbenes in Synthesis', $1^{\text {st }}$ ed., Ed. S. P. Nolan, Wiley-VCH, 2006.

[4] 'N-Heterocyclic Carbenes in Transition Metal Catalysis', Vol. 21, Ed. F. Glorius, SpringerVerlag, 2006.

[5] 'N-Heterocyclic Carbenes in Transition Metal Catalysis and Organocatalysis', Vol. 32, Ed. C. S. J. Cazin, Springer-Verlag, 2011.

[6] S. Diez-Gonzalez, N. Marion, S. P. Nolan, Chem. Rev. 2009, 109, 3613.

[7] V. Cesar, S. Bellemin-Laponnaz, L. H. Gade, Chem. Soc. Rev. 2004, 33, 619.

[8] Y. D. Ma, C. Song, C. Q. Ma, Z. J. Sun, Q. Chai, M. B. Andrus, Angew. Chem. Int. Ed. 2003, 42, 5871.

[9] D. Martin, S. Kehrli, M. d'Augustin, H. Clavier, M. Mauduit, A. Alexakis, J. Am. Chem. Soc. 2006, $128,8416$.

[10] E. P. Kundig, T. M. Seidel, Y. X. Jia, G. Bernardinelli, Angew. Chem. Int. Ed. 2007, 46, 8484.

[11] T. W. Funk, J. M. Berlin, R. H. Grubbs, J. Am. Chem. Soc. 2006, 128, 1840.

[12] Y. X. Jia, D. Katayev, G. Bernardinelli, T. M. Seidel, E. P. Kundig, Chem. Eur. J. 2010, 16, 6300.

[13] T. Jerphagnon, M. G. Pizzuti, A. J. Minaard, B. L. Feringa, Chem. Soc. Rev. 2009, 38, 1039.

[14] K. S. Lee, A. H. Hoveyda, J. Org. Chem. 2009, $74,4455$.

[15] A. J. Arduengo III, J. R. Goerlich, W. J. Marshall, J. Am. Chem. Soc. 1995, 117, 11027.

[16] A. J. Arduengo III, R. Krafczyk, R. Schmuntzler, H. A. Craig, J. R. Goerlich, W. J. Marshall, M. Unverzagt, Tetrahedron 1999, 55, 14523.

[17] M. K. Denk, A. Tadani, K. Hatano, A. J. Lough, Angew. Chem. Int. Ed. 1997, 36, 2607.

[18] M. K. Denk, A. Hezarkhani, F.-L. Zheng, Eur. J. Inorg. Chem. 2007, 3527.

[19] R. W. Alder, M. E. Blake, L. Chaker, J. N. Harvey, F. Paolini, J. Schütz, Angew. Chem. Int. Ed. 2004, 43, 5896.
[20] M. Scholl, S. Ding, C. W. Lee, R. H. Grubbs, Org. Lett. 1999, 1, 953.

[21] A. Aidouni, A. Demondeau, L. Delaude, Synlett 2006, 493.

[22] X. Luan, R. Mariz, M. Gatti, C. Costabile, A Poater, L. Cavallo, A. Linden, R. Dorta, J. Am. Chem. Soc. 2008, 130, 6848.

[23] L. Vieille-Petit, X. Luan, R. Mariz, S. Blumentritt, A. Linden, R. Dorta, Eur. J. Inorg. Chem. 2009, 1861.

[24] M. Gatti, L. Wu, E. Drinkel, F. Gaggia, S. Blumentritt, A. Linden, R. Dorta, Arkivoc 2011, 6,176 .

[25] M. S. Viciu, O. Navarro, R. F. Germaneau, O. Navarro-Fernandez, E. D. Stevens, S. P. Nolan, Organometallics 2002, 21, 5470 .

[26] M. S. Viciu, R. F. Germaneau, S. P. Nolan, $\mathrm{Org}$ Lett. 2002, 4, 4053.

[27] O. Navarro, H. Kaur, P. Mahjoor, S. P. Nolan, J. Org. Chem. 2004, 69, 3173.

[28] N. Marion, O. Navarro, J. Mei, E. D. Stevens, N. M. Scott, S. P. Nolan, J. Am. Chem. Soc. 2006, 128,4101

[29] R. H. Grubbs, Tetrahedron 2004, 60, 7117.

[30] T. Weskamp, W. C. Schattenmann, M. Spiegler, W. A. Herrmann, Angew. Chem. Int. Ed. 1998, 37, 2490.

[31] J. K. Huang, E. D. Stevens, S. P. Nolan, J. L. Petersen, J. Am. Chem. Soc. 1999, 121, 2674.

[32] M. Scholl, S. Ding, C. W. Lee, R. H. Grubbs, Org. Lett. 1999, 1, 953.

[33] C. Schneider, J. Brauner, Tetrahedron Lett. 2000, 41, 3043.

[34] C. Schneider, J. Brauner, Eur. J. Org. Chem. 2001, 4445.

[35] H. Zhou, J. Campbell, S. T. Nguyen, Org. Lett. 2001, 3, 2229.

[36] L. Vieille-Petit, X. Luan, M. Gatti, S. Blumentritt, A. Linden, H. Clavier, S. P. Nolan, R. Dorta, Chem. Commun. 2009, 3783.

[37] L. Vieille-Petit, H. Clavier, A. Linden, S. Blumentritt, S. P. Nolan, R. Dorta, Organometallics 2010, 29, 775.

[38] H. Wakamatsu, S. Blechert, Angew. Chem. Int Ed. 2002, 41, 2403.

[39] M. Gatti, L. Vieille-Petit, X. Luan, R. Mariz, E. Drinkel, A. Linden, R. Dorta, J. Am. Chem. Soc. 2009, 131, 9498

[40] M. Gatti, E. Drinkel, L. Wu, I. Pusterla, F. Gaggia, R. Dorta, J. Am. Chem. Soc. 2010, 132, 15179.

[41] M. G. Organ, S. Calimsiz, M. Sayah, K. H. Hoi, A. J. Lough, Angew. Chem. Int. Ed. 2009, 48, 2383.

[42] W. Tang, A. G. Capacci, X. Wei, W. Li, A. White, N. D. Patel, J. Savoie, J. J. Gao, S. Rodriguez, B. Qu, N. Haddad, B. Z. Lu, D. Krishnamurthy, N. K. Yee, C. H. Senanayake, Angew. Chem. Int. Ed. 2010, 49, 5879.

[43] L. Wu, E. Drinkel, F. Gaggia, S. Capolicchio, A. Linden, L. Falivene, L. Cavallo, R. Dorta, Chem. Eur. J. 2011, accepted for publication.

[44] X. Luan, R. Mariz, C. Robert, M. Gatti, S Blumentritt, A. Linden, R. Dorta, Org. Lett. 2008, 10, 5569.

[45] X. Luan, L. Wu, E. Drinkel, R. Mariz, M. Gatti, R. Dorta, Org. Lett. 2010, 12, 1912.

[46] 'Catalytic Asymmetric Synthesis', $3^{\text {rd }}$ ed., Ed. I. Ojima, Wiley-VCH, 2010.

[47] 'Comprehensive Asymmetric Catalysis', Eds. E. N. Jacobsen, A. Pfaltz, H. Yamamoto, Springer-Verlag, 1999.

[48] H. B. Henbest, J. Trocha-Grimshaw, J. Chem. Soc., Perkin Trans. I 1974, 601

[49] H. B. Henbest, J. Trocha-Grimshaw, J. Chem Soc., Perkin Trans. I 1974, 607.

[50] Y. M. Y. Haddad, H. B. Henbest, J. Husbands, T. R. B. Mitchell, J. Trocha-Grimshaw, J. Chem. Soc., Perkin Trans. I 1974, 596.

[51] B. R. James, R. S. McMillan, Can. J. Chem. 1977, 55, 3927.

[52] B. R. James, R. H. Morris, J. Chem. Soc., Chem. Commun. 1978, 929 
[53] N. Khiar, I. Fernandez, F. Alcudia, Tetrahedron Lett. 1993, 34, 123.

[54] J. V. Allen, J. F. Bower, J. M. J. Williams, Tetrahedron: Asymmetry 1994, 5, 1895.

[55] K. Hiroi, Y. Suzuki, Tetrahedron Lett. 1998, 39 , 6499.

[56] K. Hiroi, Y. Suzuki, I. Abe, Y. Hasegawa, K. Suzuki, Tetrahedron: Asymmetry 1998, 9, 3797.

[57] D. G. I. Petra, P. C. J. Kamer, A. L. Spek, H. E. Schoemaker, P. W. N. M. van Leeuwen, J. Org. Chem. 2000, 65, 3010.

[58] K. Hiroi, Y. Suzuki, I. Abe, R. Kawagishi, Tetrahedron 2000, 56, 4701.

[59] K. Hiroi, I. Izawa, T. Takizawa, K. Kawai, Tetrahedron 2004, 60, 2155.

[60] J. Chen, D. Li, H. Ma, L. Cun, J. Zhu, J. Deng, J. Liao, Tetrahedron Lett. 2008, 49, 6921.

[61] J. Chen, F. Lang, D. Li, L. Cun, J. Zhu, J. Deng, J. Liao, Tetrahedron: Asymmetry 2009, 20, 1953.

[62] R. Mariz, X. Luan, M. Gatti, A. Linden, R. Dorta, J. Am. Chem. Soc. 2008, 130, 2172.

[63] A. Miyashita, A. Yasuda, H. Takaya, K. Toriumi, T. Ito, T. Souchi, R. Noyori, J. Am. Chem. Soc. 1980, 102, 7932 .
[64] R. Schmid, M. Cereghetti, B. Heiser, P. Schönholzer, H.-J. Hansen, Helv. Chim. Acta 1988, 71, 897.

[65] R. Mariz, J. Bürgi, M. Gatti, E. Drinkel, X. Luan, A. Linden, R. Dorta, Angew. Chem. Int. Ed. 2009, 48, 2768.

[66] R. Mariz, J. Bürgi, M. Gatti, E. Drinkel, X. Luan, R. Dorta, Chimia 2009, 63, 508.

[67] R. Mariz, A. Poater, M. Gatti, E. Drinkel, J. J. Bürgi, X. Luan, S. Blumentritt, A. Linden, L. Cavallo, R. Dorta, Chem. Eur. J. 2010, 16, 14335.

[68] It should be pointed out that such a direct comparison of different ligand families can be misleading. For a recent computational analysis on the subject, see: D. G. Gusev, Organometallics 2009, 28, 763 .

[69] T. Hayashi, M. Takahashi, Y. Takaya, M. Ogasawara, J. Am. Chem. Soc. 2002, 124, 5052.

[70] A. Kina, H. Iwamura, T. Hayashi, J. Am. Chem. Soc. 2006, 128, 3904

[71] A. Poater, F. Ragone, R. Mariz, R. Dorta, L. Cavallo, Chem. Eur. J. 2010, 16, 14348. 